\title{
P01-043 - Comparative characteristic of FMF and FMF with HSP
}

\author{
H Sargsyan ${ }^{1 *}, \mathrm{P}$ Ghazaryan ${ }^{2}$ \\ From 7th Congress of International Society of Systemic Auto-Inflammatory Diseases (ISSAID) \\ Lausanne, Switerland. 22-26 May 2013
}

\section{Introduction}

According the literature data about Familial Mediterranean fever (FMF), with the combination of Henoch- Sheilen purpura (HSP), as well as the results of the work done by the former of our studies we attempt to identify and compare membranes aspects of pathogeneses of FMF and combination of FMF with HSP.

\section{Objectives}

The aim of our study is to identify speed of lipid peroxidation (LPO) and the role of degradation of membrane phospholipids (PL) of FMF and combination of FMF with HSP.

\section{Methods}

Clinical studies conducted in 61 non complicated of amyloidosis FMF children in the Republican FMF Children Center, Center "Arabkir". The age of the patients varies from 5-15. Three patients of FMF are accompanied with HSP. We are selected as a control group of 11 healthy people in practice.Biochemical studies carried out in Hematological Center of Armenia. In erythrocytes of membrane we determine the following index: phospholipase $\mathrm{A}_{2}$ activity, intensity of LPO, as well as the level of citotoxic - Lysophatidylcholines( LysoPCH ). The activity of phospholipase $\mathrm{A}_{2}$ and LPO was determined by the spektrofotometrik methods. The fractions of separate PL in erythrocyte membranes were carried out by thin-layer chromatography methods.

\section{Results}

The results of our research showed that FMF is followed by rising the activity of phospholipase $\mathrm{A}_{2}$ (approximately two times, $\mathrm{P}<0,001)$, with sharp increase of citotoxicLysoPCH $(\mathrm{P}<0,001)$ and intensity of LPO (about 3 times,
$\mathrm{P}<0,001)$.It is noteworthy, that in the second group of our patients (FMF with HSP) these indices will be raised. Therefore, the mentioned follows that the second group of patients treatment is more difficult and requires a special, single-minded approach.

\section{Conclusion}

The results in our experience are discussed to find possible ways of increasing efficiency of treatment FMF with HSP.

\section{Disclosure of interest}

None declared.

\section{Authors' details}

${ }^{1}$ Yerevan State Medical University, Yerevan, Armenia. ${ }^{2}$ Haematological Centre, Yerevan, Armenia.

Published: 8 November 2013

doi:10.1186/1546-0096-11-S1-A46

Cite this article as: Sargsyan and Ghazaryan: P01-043 - Comparative

characteristic of FMF and FMF with HSP. Pediatric Rheumatology 201311 (Suppl 1):A46.

${ }^{1}$ Yerevan State Medical University, Yerevan, Armenia

Full list of author information is available at the end of the article 